\title{
Medication adherence behaviors of Medicare
} beneficiaries

This article was published in the following Dove Press journal:

Patient Preference and Adherence

17 September 2014

Number of times this article has been viewed

\author{
Sian M Carr-Lopez' \\ Allen Shek' \\ Janine Lastimosa ${ }^{2}$ \\ Rajul A Patel' \\ Joseph A Woelfel' \\ Suzanne M Galal' \\ Berit Gundersen' \\ 'Pharmacy Practice Department, \\ ${ }^{2}$ Thomas J Long School of Pharmacy \\ and Health Sciences, University of the \\ Pacific, Stockton, CA, USA
}

Background: Medication adherence is crucial for positive outcomes in the management of chronic conditions. Comprehensive medication consultation can improve medication adherence by addressing intentional and unintentional nonadherence. The Medicare Part D prescription drug benefit has eliminated some cost barriers. We sought to examine variables that impact self-reported medication adherence behaviors in an ambulatory Medicare-beneficiary population and to identify the factors that influence what information is provided during a pharmacist consultation.

Methods: Medicare beneficiaries who attended health fairs in northern California were offered medication therapy management (MTM) services during which demographic, social, and health information, and responses to survey questions regarding adherence were collected. Beneficiaries were also asked which critical elements of a consultation were typically provided by their community pharmacist. Survey responses were examined as a function of demographic, socioeconomic, and health-related factors.

Results: Of the 586 beneficiaries who were provided MTM services, 575 (98\%) completed the adherence questions. Of responders, 406 (70\%) reported taking medications "all of the time". Of the remaining $169(30 \%)$, the following reasons for nonadherence were provided: $123(73 \%)$ forgetfulness; 18 (11\%) side effects; and $17(10 \%)$ the medication was not needed. Lower adherence rates were associated with difficulty paying for medication, presence of a medication-related problem, and certain symptomatic chronic conditions. Of the 532 who completed survey questions regarding the content of a typical pharmacist consultation, the topics included: 378 (71\%) medication name and indication; 361 (68\%) administration instructions; 307 (58\%) side effects; 257 (48\%) misseddose instructions; and 245 (46\%) interactions. Subsidy recipients and non-English speakers were significantly less likely to be counseled on drug name, indication, and side effects. The presence of certain health conditions was also associated with missing consultation elements.

Conclusion: While Medicare beneficiaries are generally adherent to medication therapy, adherence barriers must be identified and addressed during comprehensive medication consultation.

Keywords: pharmacist consultation, adherence behaviors

\section{Background}

In 2003, the World Health Organization produced a report entitled "Adherence to Long-Term Therapies: Evidence for Action", in which the average adherence rate to therapies for chronic conditions in developed countries was a sobering $50 \%$. ${ }^{1}$ The report emphasized that the cause of poor adherence does not reside with the patient but rather, with the health system. It identified the importance of a health care team that includes the patient and that has training in adherence strategies. The report also called for additional assessments, not only of adherence rates, but also, of the factors that impact it. Adherence rates in the Medicare population have already been examined. In 2013, a report was published regarding medication adherence in all
Correspondence: Suzanne M Gala and Health Sciences, University of the Pacific, 75I Brookside Rd, Stockton CA, 9521 I, USA

Tel +I 2099463918

Fax + I 2099462402

Email sgalal@pacific.edu 
50 States. In addition to other adherence measures, medication possession ratios, defined as the ratio of the total days the member had drug available to the number of possible days the member could have drug on hand, were reported. ${ }^{2}$ The report provided a state-wide average, adjusted for age and sex. The results provide a comparison of adherence rates in three distinct market segments: Medicare Part D (MPD) beneficiaries, employer health plan holders, and personal health plan holders. Adherence rates were highest in the MPD population.

Poor adherence increases the risk of morbidity, hospitalization, and mortality, thus has clear implications for worsening health outcomes as well as increasing health care costs. ${ }^{3}$ In four common conditions - hypertension, diabetes, hyperlipidemia, and heart failure - higher levels of medication adherence have been found to be associated with lower hospitalization rates. ${ }^{4}$ Medication nonadherence has been estimated to cost the health care system approximately $\$ 100$ billion in hospitalizations annually and $\$ 2,000$ per patient year in excess physician visits. ${ }^{5}$ An estimate of excess health care costs in the United States due to medication nonadherence approaches $\$ 290$ billion annually. ${ }^{6}$ In a review of the predictors of adherence, Touchette and Shapiro reported that lower adherence rates are associated with increased complexity of the drug regimen and other factors, including number of medications, poor patient-provider relationship, lower socioeconomic status, poor prescription drug coverage, presence of medication side effects, living alone, and treatment of asymptomatic conditions and specific health conditions, such as depression and cognitive impairment. ${ }^{7}$ Other risk factors associated with poor adherence include confusion or forgetfulness, language barriers, and "feeling well enough to forgo taking the medication". ${ }^{6}$ Medication cost, including copayments, contributes to medication nonadherence in uninsured, elderly, indigent, and homeless populations, but also, in middle-income patients with prescription coverage and Medicare recipients..$^{8-11}$

In 2006, the MPD benefit was introduced to help beneficiaries pay for their outpatient prescription medications. However, with the advent of MPD, may have come complacency with respect to the identification and resolution of cost-related barriers to medication adherence. Beneficiaries of MPD may still have difficulty with their medication costs and may therefore benefit from additional governmental assistance, either Medicaid or the Low-Income Subsidy. In this manuscript, subsidy recipients refers to those beneficiaries who had either Medicaid or the Low-Income Subsidy. While MPD removed many cost related barriers to medication adherence, it also created one for beneficiaries who enter the coverage gap known as the "Donut Hole" - during this time, many patients become nonadherent to their medication therapy, as they are unable to pay for their share of prescription costs. ${ }^{12}$ In 2013, there were over 50 million Medicare beneficiaries, and this number is projected to grow to 72 million by $2030 .{ }^{13}$ Considering that Medicare beneficiaries who qualify for coverage based on their age (65+ years of age) take a significant number of medications in comparison with other age groups, it is critical to focus on this population in order to identify and solve issues relating to nonadherence.

Nonadherence can be classified as either unintentional or intentional. Unintentional nonadherence refers to a patient forgetting to take their medication(s), while intentional nonadherence refers to the patient weighing the pros and cons of taking a medication, and consciously deciding not to adhere to the medication regimen. ${ }^{14}$ Pharmacist consultation provides patients with information and strategies to optimize medication-related outcomes. Both types of nonadherence require distinct methods to address and correct the issue. ${ }^{14,15}$ A previous review of medication adherence from the pharmacist perspective discussed mechanisms for assessing adherence and persistence, and strategies for improving adherence. ${ }^{16}$ While many sophisticated and expensive methods of monitoring adherence are available, patient self-reporting remains the most common and least expensive means of assessing adherence. The factors impacting adherence that were discussed in the review included adverse effects of medication, perceived lack of effect, complexity of the regimen, asymptomatic conditions, physical limitations, psychiatric conditions, individual perceptions, family or cultural issues, and functional health literacy. The authors concluded that regardless of the various factors that contribute to nonadherence, effective communication between the pharmacist, patient, and other health care providers is critical. Use of open-ended questions in discussions, patient education on key consultation points, and provision of follow up was recommended. The authors further concluded that clarification of instructions, particularly for the elderly or patients with cognitive impairment, and scheduled follow up is essential.

Optimal health care requires a team-based approach, and pharmacists are recognized as an integral part. ${ }^{17}$ Pharmacists are ideally situated to provide consultation to patients in the community setting. A comprehensive meta-analysis regarding the effects of pharmacist-provided patient care showed statistically significant beneficial outcomes in all three domains of therapeutic, safety, and humanistic outcomes, including medication adherence. ${ }^{18}$ Patients indicated that the top consultation elements expected to be provided during their medication consultation included adverse effects, directions for use, drug interaction with prescription drugs, drug indication, and 
special instructions for unique prescriptions. ${ }^{19,20}$ However, deficiencies in patient consultation may translate to medication nonadherence. Studies conducted to examine this issue have identified several barriers that prevent patients from asking their pharmacists for a consultation. Patient barriers include fear of embarrassment, time constraints, and lack of initiative, education, or perceived need. In some cases, patients indicated that they trusted the physician to provide the needed information or that written information would be adequate. Lastly, the pharmacy may lack privacy or the pharmacist may be perceived as unapproachable. ${ }^{19-22}$ In order to decrease unintended medication-related outcomes and increase medication adherence, further examination of pharmacists' consultation from the patient's perspective is critical.

The objective of this study was to determine variables that impact self-reported medication adherence behaviors in an ambulatory Medicare population. Since nonadherence can be impacted by knowledge of the medication, factors that impact information provided during pharmacist consultations with this population were also examined.

\section{Methods}

This study was conducted with the approval of the Institutional Review Board of the University of the Pacific. Twelve community outreach events were conducted during the 2013 MPD Open Enrollment Period in six central and northern California cities. Medication therapy management (MTM) was offered to all beneficiaries taking at least one medication. MTM was conducted by student pharmacists under the supervision of licensed pharmacists. During MTM, patients were asked to provide verbal informed consent and were invited to answer a series of survey questions asked by student pharmacists. Participants were given the option of not answering each of the questions and were informed that they could stop answering questions at any time and still receive all services, without penalty. A standardized data collection tool was used to collect demographic information, social history, subsidy status, and medication and disease state information, and to document answers to survey questions. Each beneficiary was asked "Which of the following best describes how often you take your medications as directed". Answer options included: "all of the time"; "most of the time"; "some of the time"; and "none of the time". A beneficiary who responded with anything other than "all of the time", was then asked "What is/are the main reason(s) that you do not take your medication as directed?" The respondent could select any (or all) option(s) that applied from the following, including: "I forget to take my medications"; "I do not get my medication refilled on time"; "I experience side effects"; "I do not know what the medication is for"; "I do not think I need it"; "I do not think it is helping me"; "I want to save some for later"; or "I cannot afford it".

Next, an assessment of critical elements of pharmacist consultation was conducted. Beneficiaries were asked "Which of the following is typically discussed in a consultation with your pharmacist?" Beneficiaries answered "yes" or "no" to each element. The elements included: "What the medication is called and what it is used for"; "How and when you should take it and for how long"; "What you should do if you miss a dose"; "What the side effects are"; and "Whether it is safe to take with other medicines or vitamins".

Descriptive statistics were reported for beneficiary demographic and clinical characteristics. Each demographic and clinical characteristic was analyzed to determine its effect on adherence. Chronic conditions were also evaluated to determine their association with self-reported adherence. Chisquare and Fisher's exact tests were used for each variable, to compare those who reported taking medication all of the time with those who reported taking medication less than all of the time. The Mann-Whitney test was used to evaluate the effects of self-reported adherence as a function of level of education, number of chronic medications, and number of chronic conditions. Variables that could impact whether critical consultation elements were provided were also analyzed using inferential statistics. Chi-square and Fisher's exact tests were used to examine the differences in what was typically discussed during a pharmacist consultation as a function of demographic and clinical characteristics. Alpha was set a priori to 0.05 . Statistics were performed via IBM SPSS Statistics for Windows, Version 20 (IBM Corp, Armonk, NY, USA).

\section{Results}

A total of 1,547 Medicare beneficiaries attended the outreach events; of those, 586 were provided MTM services. Of the beneficiaries who were provided MTM services, 575 (98\%) completed the questions regarding medication adherence, and $532(91 \%)$ completed the survey questions regarding pharmacist consultations. Demographic and clinical characteristics are provided in Table 1 .

When asked about medication adherence, 406 (71\%) reported taking their medication "all the time", 143 (25\%) reported taking their medication "most of the time", and $26(4 \%)$ reported taking their medication "some of the time". No individuals reported taking their medication "none of the time". For the 169 (29\%) beneficiaries who reported not taking medication all of the time, the reasons given are summarized in Table 2. Statistical analysis identified that difficulty paying for medications and the presence of 
Table I Demographics and clinical characteristics $(\mathrm{N}=586)$

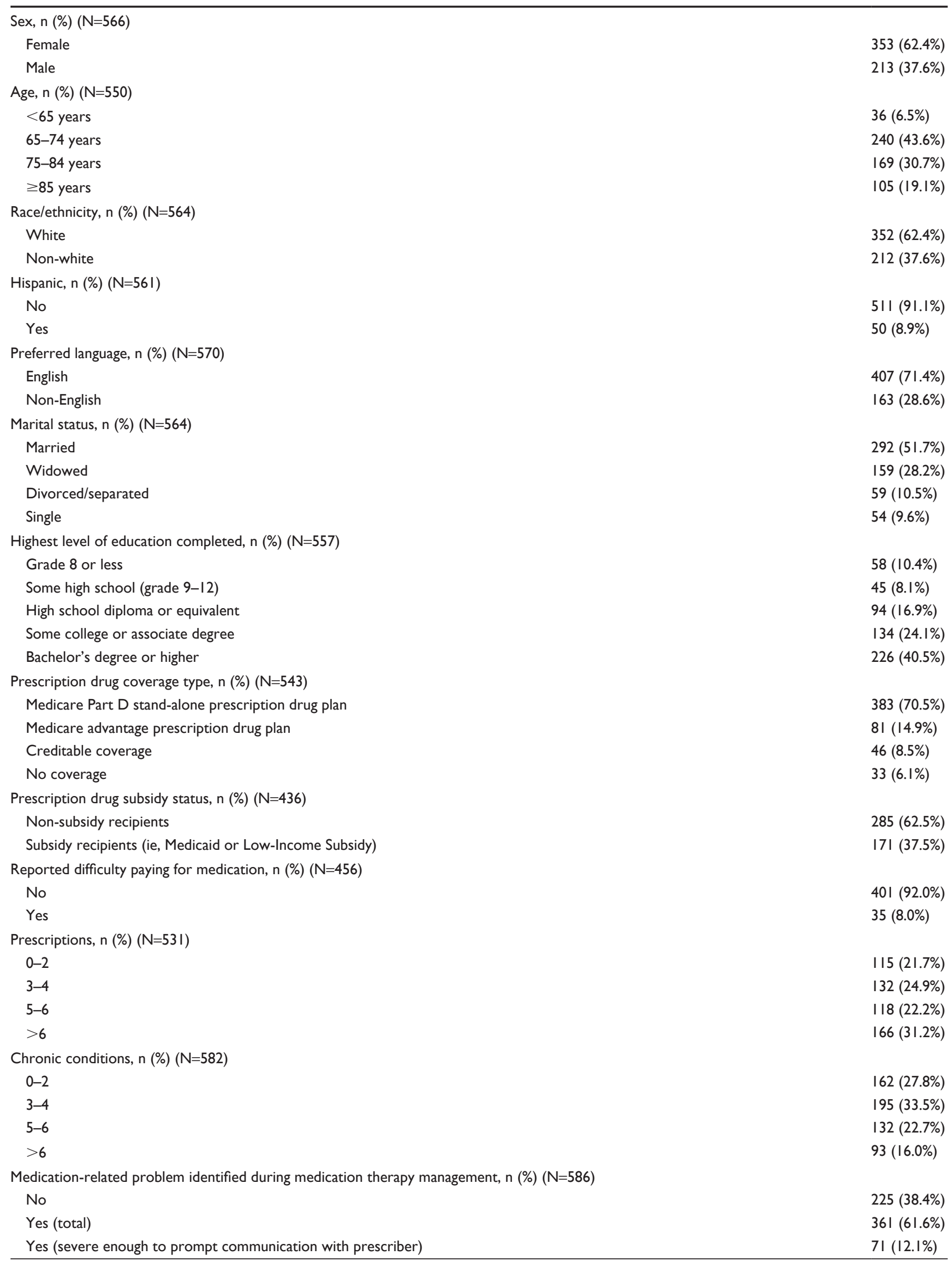


Table 2 Reported reasons for medication nonadherence $(\mathrm{N}=169)$

\begin{tabular}{ll}
\hline Reason stated & $\mathbf{N}(\%)^{*}$ \\
\hline Forget to take & $123(72.8 \%)$ \\
Worrisome side effect & $18(10.7 \%)$ \\
Do not think it is needed & $17(10.1 \%)$ \\
Other & $13(7.7 \%)$ \\
Did not get refill in time & $7(4.1 \%)$ \\
Cannot afford it & $7(4.1 \%)$ \\
Do not think it is helping & $2(1.2 \%)$ \\
Do not know what it is for & $\mathrm{I}(0.6 \%)$ \\
Wanted to save some for later & $\mathrm{I}(0.6 \%)$ \\
\hline Note: $*$ Participants could select more than one reason for medication nonadherence.
\end{tabular}

specific symptomatic medical conditions were associated with medication nonadherence. Additionally, beneficiaries for whom a medication-related problem was identified during the MTM session were found to be significantly less likely to be adherent with their medication(s). The factors that were statistically significantly associated with suboptimal medication adherence are shown in Table 3.

Beneficiaries reported that critical elements were included in a typical pharmacist consultation between $46 \%$ and $71 \%$ of the time (Table 4). There was no statistically significant difference between sex, race/ethnicity, education level, prescription drug coverage type, number of prescription medications, or the presence of chronic conditions, such as hypertension, hyperlipidemia, or diabetes mellitus, in relation to pharmacist consultative elements. Subsidy recipients were less likely to report receiving elements of the pharmacist consultation, including medication name and indication $(P=0.008)$ and consultation about side effects $(P=0.006)$. Beneficiaries who spoke a language other than English were less likely to receive consultation regarding medication name and indication ( $P=0.014)$ or consultation about side effects $(P=0.009)$. Further analysis revealed that beneficiaries who were subsidy recipients were significantly more likely to be non-English speakers $(P<0.001)$. Certain health conditions, including benign prostatic hypertrophy, cancer, incontinence, and dementia, were associated with significantly more missing elements of

Table 3 Factors associated with lower self-reported medication adherence

\begin{tabular}{ll}
\hline Variable & $\boldsymbol{P}_{\text {-value }}$ \\
\hline Difficulty paying for medications & 0.01 \\
Medication-related problem identified during & 0.008 \\
medication therapy management & \\
Beneficiaries with gastroesophageal reflux disease & 0.005 \\
Beneficiaries with coronary heart disease & 0.012 \\
Beneficiaries with asthma & 0.007 \\
Beneficiaries with anxiety & 0.01 \\
Beneficiaries with allergic rhinitis & 0.002 \\
\hline
\end{tabular}

Note: Pearson's chi-square. the pharmacist consultation. In addition, our research identified that advancing age was associated with more missing elements for all critical components of the pharmacist consultation, some reaching statistical significance (Table 5).

\section{Discussion}

In our study population, level of education, sex, age, marital status, race/ethnicity, number of chronic medications or conditions, preferred language, or subsidy status were not significantly associated with self-reported medication adherence. Our findings may differ from those of other studies in that within our population, less than $7 \%$ were younger than 65 years, and $40 \%$ reported obtaining a bachelor's degree or higher. Three factors were statistically associated with less than optimal adherence. These included some symptomatic conditions, issues related to paying for medication, and identifying medication-related problems during MTM. Our study identified an association between lower adherence rates in beneficiaries with symptomatic conditions, such as gastroesophageal reflux disease, coronary heart disease, asthma, allergic rhinitis, and anxiety. In our population, there was no association with depression or asymptomatic conditions, such as hyperlipidemia or hypertension and poor adherence, contrary to findings reported elsewhere. ${ }^{7}$ It is possible that some patients with symptomatic conditions may be inclined to take prescribed medications when experiencing symptoms, rather than routinely as prescribed. In order to ensure that patients are adherent for chronic but episodically symptomatic conditions, pharmacists should include the reason the drug is being prescribed as part of the consultation. In our study population, $70 \%$ of patients recalled that drug name and indication were included in the pharmacist consultation. Among, the participants in our study population who reported taking their medication less than all of the time, thinking that the medication was not needed was reported as one of the top three reasons. Another study has reported that the primary reason for intentional nonadherence was a belief that the medication is not needed. ${ }^{23}$ Without a clear understanding of the purpose of the medication, patients may fail to adhere properly and eventually require emergent care or hospitalizations, to manage a poor medication outcome caused by intentional nonadherence.

Cost of medication, even with the MPD prescription drug benefit, was a barrier to adherence in our study population. This finding is consistent with those reported by others. ${ }^{11,16}$ In terms of overcoming cost barriers that lead to medication nonadherence, pharmacists or other patient advocates can provide assistance by ensuring that individuals are in the lowest MPD cost plan, enrolling beneficiaries into pharmaceutical assistance programs, or assisting individuals to apply for 
Table 4 Effects of chronic diseases on information provided during pharmacist consultation: percent of Medicare beneficiaries who reported they received consultation elements

\begin{tabular}{|c|c|c|c|c|c|}
\hline & $\begin{array}{l}\text { Drug name and } \\
\text { indication }\end{array}$ & $\begin{array}{l}\text { How to } \\
\text { take }\end{array}$ & $\begin{array}{l}\text { Missed } \\
\text { dose }\end{array}$ & Side effects & $\begin{array}{l}\text { Safe to take with } \\
\text { other medicine }\end{array}$ \\
\hline Overall population & $71 \%$ & $68 \%$ & $48 \%$ & $58 \%$ & $46 \%$ \\
\hline Beneficiaries with cancer & $69 \%$ & $53 \%^{\mathrm{a}}$ & $47 \%$ & $49 \%$ & $40 \%$ \\
\hline Beneficiaries with incontinence & $64 \%$ & $55 \%$ & $32 \%$ & $48 \%$ & $30 \%{ }^{c}$ \\
\hline Beneficiaries with benign prostatic hypertrophy & $56 \%^{\mathrm{d}}$ & $58 \%$ & $44 \%$ & $48 \%$ & $40 \%$ \\
\hline Beneficiaries with dementia & $50 \%$ & $50 \%$ & $20 \%$ & $37 \%$ & $32 \%$ \\
\hline
\end{tabular}

Notes: Pearson's chi-square. ${ }^{\mathrm{a} P}=0.046 .{ }^{\mathrm{b}} P=0.017 .{ }^{\mathrm{c}} P=0.023 .{ }^{\mathrm{d}} P=0.019 .{ }^{\mathrm{e}} P=0.035 .{ }^{\mathrm{f}} P=0.009$.

the Low-Income Subsidy. Approximately $90 \%$ of Medicare beneficiaries could reduce their out-of-pocket prescription drug costs by annually reviewing their MPD plan. ${ }^{24}$

The patients in our study who had a medication-related problem identified during the MTM process were statistically more likely to report less than optimal adherence. Experiencing a worrisome side effect was the second most common reason stated for nonadherence in our population. Beneficiaries in this study were offered MTM if they were taking one or more medications. The current inclusion criteria for MTM from the Centers for Medicare and Medicaid (CMS) allow MPD plan sponsors to require that patients take up to eight medications in order to meet the drug requirement for provision of MTM services. ${ }^{25} \mathrm{CMS}$ data from 2012 reveal that $75 \%$ of MPD plan sponsors required a beneficiary to be taking seven or eight medications to qualify for MTM. The ability of pharmacists to provide MTM to a greater number of Medicare beneficiaries and therefore identify and resolve medication-related problems has the potential to improve adherence. ${ }^{26} \mathrm{~A}$ recent brief from the New England Healthcare Institute acknowledged the value of MTM to improve adherence and, ultimately, health care outcomes but recognized the hesitance from stakeholders, particularly payers, to implement MTM on a broader scale. ${ }^{27}$

Advancing age was associated with lower reported rates of comprehensive consultation. Considering that most Medicare beneficiaries are over the age of 65 years, it is possible that our findings may reflect memory decline associated with advancing age or dementia and that beneficiaries did not recall elements covered in the consultation, or that advancing age impacts what pharmacists discuss in a consultation. Forgetting to take medication was the most common reason for nonadherence reported by our study participants. One study reported that $70 \%$ of community dwelling seniors use a pillbox. ${ }^{28}$ Memory aids, medication reminders, and other adherence strategies should be offered, to minimize this form of unintentional nonadherence. Subsidy recipients and MDP beneficiaries who spoke a language other than English were less likely to receive elements of the pharmacist consultation; however, further analysis revealed that beneficiaries who were subsidy recipients were significantly more likely to be non-English speakers, suggesting it may be the language barrier that produced the results.

Our research identified that although pharmacists generally include essential information that patients desire during a consultation, critical elements of medication consultation were omitted between $29 \%$ and $52 \%$ of the time. Pharmacist discomfort or lack of privacy may be contributing to the omission of consultation elements for specific conditions such as dementia, incontinence, and benign prostatic hypertrophy. Our research also found that patients with cancer were less likely to be counseled on how to take the drug and for how long. This may relate to a lack of knowledge by pharmacists about cancer therapy regimens. ${ }^{29}$

Considered to be the most accessible of the health care providers, pharmacists play an important role in the management of patients' health, particularly as it relates to the medication regimen. In a published review of medication adherence from the pharmacist perspective, recommended strategies to improve adherence include ensuring effective

Table 5 Effect of age on information provided during pharmacist consultation: Percentage of Medicare beneficiaries in each age category who reported they received consultation elements

\begin{tabular}{lllll}
\hline Element of consultation & $\mathbf{6 5 - 7 4}$ years & $\mathbf{7 5 - 8 4}$ years & $\geq \mathbf{8 5}$ years $^{\boldsymbol{P}_{\text {-value }}}$ \\
\hline Drug name and indication & $\mathbf{7 8 \%}$ & $68 \%$ & $63 \%$ & 0.038 \\
How to take & $\mathbf{7 6 \%}$ & $67 \%$ & $52 \%$ & 0.001 \\
Missed dose & $54 \%$ & $46 \%$ & $39 \%$ & 0.055 \\
Side effects & $63 \%$ & $57 \%$ & $46 \%$ & 0.049 \\
Safe to take with other medicine & $52 \%$ & $46 \%$ & $35 \%$ & 0.080 \\
\hline
\end{tabular}

Note: a Mann-Whitney. 
communication between the pharmacist, patient, and providers; use of nonjudgmental, open discussions; provision of clarifying instructions; and use of scheduled follow up, to provide additional support. ${ }^{16}$

In our population, mechanisms to enhance adherence could include medication education, medication reminders, elimination of cost barriers, and identification and resolution of side effects or other medication-related problems. Considering there are two types of nonadherence, intentional and unintentional, mechanisms to overcome barriers must be tailored to the cause. By using an empathic, patient-centric communication style, clinicians may be more effective in identifying the presence of intentional and unintentional nonadherence and tailoring interventions to the needs of patients. ${ }^{15}$

\section{Limitations}

There are several limitations to this study. The use of a survey to assess adherence relied on study participants' self-reported behavior; objective measurements or validation of actual adherence rates were not conducted as our objective was to identify variables associated with nonadherence, rather than to determine adherence rates. Self-reported adherence data gathered from patient interviews have historically overestimated adherence rates. ${ }^{16}$ Our survey was not a validated or commercially available tool. While a validated adherence assessment questionnaire could have been used to determine the adherence rate, additional questions would have to have been asked in order to identify other variables associated with nonadherence. The Medication Adherence Questionnaire (MAQ) is a validated tool most commonly used because of its short length, ease of scoring, and previous validation in patients with a variety of chronic conditions. ${ }^{30,31}$ Our survey included variables that are assessed by the MAQ, such as forgetfulness, beliefs about the need for the medication, and presence of adverse effects, but we added items, including being unable to afford the medication. We did not assess adherence to individual medication but rather, to the medication regimen in general and thus are unable to make determinations about adherence variables for individual medications.

Study participants were asked about a typical community pharmacist consultation. Again, this process relied on the individual's ability to recall what was included in the consultation, introducing potential recall bias. Direct observation of pharmacists' consultations was not done. Nonetheless, the provision of patients' perspectives on what they remember from a consultation is an important contribution to the literature.

Our study surveyed Medicare beneficiaries from one geographic area that included northern and central California. Our population was predominantly white, and $40 \%$ reported attaining a college degree. Thus the applicability of our findings to other Medicare populations may be limited.

The study identified factors in a Medicare population that were statistically associated with reduced adherence as well as noncomprehensive consultation by pharmacists. An examination of the effectiveness of interventions to enhance adherence is needed. Comprehensive consultation by pharmacists for all beneficiaries is desirable, but systematic supports, such as improved privacy, resources for consultations conducted in languages other than English, and strategies for effective targeting of unintentional nonadherence related to forgetfulness are needed.

\section{Conclusion}

This study adds to our understanding of self-reported adherence behaviors in an ambulatory Medicare population. The $30 \%$ of Medicare beneficiaries in our study population who reported not taking medication as prescribed all of the time provided reasons and thus, opportunities to enhance medication adherence. The top three reasons for nonadherence included forgetting to take medication, not taking medication due to a worrisome side effect, and belief that the medication was not needed. A statistical analysis identified factors that were associated with medication nonadherence, including patients with specific health conditions, patients who had a medicationrelated problem identified during medication therapy management, and those who reported difficulty paying for medication, even with the MPD benefit. While Medicare beneficiaries are generally more adherent to medication therapy than other groups, barriers must be identified and addressed. An effective, comprehensive pharmacist consultation could successfully address many of these barriers and provide an opportunity to optimize drug therapy outcomes. Our study revealed that limited economic means (Medicaid or Low-Income Subsidy recipients) and preferred language other than English were associated with lower rates of consultation discussion regarding drug name and indication, and side effects. Further research is required to examine factors that lead to nonadherence and to assess the effectiveness of interventions designed to improve patient well-being and avoid unnecessary health care spending. Next steps should include examination of the effectiveness and acceptability of different memory aids in the Medicare population, a prospective examination of which counseling elements are being covered in a pharmacist consultation for this population, and lastly, examination of how often the consultation elements should be repeated to optimize retention and thus, support optimal adherence.

\section{Disclosure}

The authors report no conflicts of interest in this work. 


\section{References}

1. World Health Organization. Adherence to Long-Term Therapy: Evidence for Action. Geneva: World Health Organization; 2003. Available from: http://www.who.int/chp/knowledge/publications/ adherence_full_report.pdf?ua=1. Accessed October 22, 2013.

2. CVS Caremark Pharmacy Care Research Institute. 2013 State of the States: Adherence Report. Woonsocket, RI: CVS Caremark; 2013. Available from: http://investors.cvscaremark.com/ /media/Files/C/CVS-IR/reports/ sos-adherence-report-2013.pdf. Accessed November 1, 2013.

3. Chisholm-Burns MA, Spivey CA. The 'cost' of medication nonadherence: consequences we cannot afford to accept. $J$ Am Pharm Assoc (2003). 2012;52(6):823-826.

4. Sokol MC, McGuigan KA, Verbrugge RR, Epstein RS. Impact of medication adherence on hospitalization risk and healthcare cost. Med Care. 2005;43(6):521-530.

5. Pharmaceutical Research and Manufacturers of America. Improving prescription medicine adherence is key to better health care: Taking medicines as prescribed can lower costs and improve health outcomes. Washington, DC: Pharmaceutical Research and Manufacturers of America. 2011. Available from: http://www.phrma.org/sites/default/ files/pdf/PhRMA_Improving\%20Medication\%20Adherence_Issue $\% 20$ Brief.pdf. Accessed June 23, 2014.

6. New England Healthcare Institute (NEHI). Thinking Outside the Pillbox: A System-wide Approach to Improving Patient Medication Adherence for Chronic Disease. Cambridge, MA: New England Healthcare Institute; 2009. Available from: http://www.nehi.net/writable/publication_ files/file/pa_issue_brief_final.pdf. Accessed July 24, 2013.

7. Touchette DR, Shapiro NL. Medication compliance, adherence, and persistence: Current status of behavioral and educational interventions to improve outcomes. J Manag Care Pharm. 2008;14(6 Suppl S-d):S2-S10.

8. MacLaughlin EJ, Raehl CL, Treadway AK, Sterling TL, Zoller DP, Bond CA. Assessing medication adherence in the elderly: which tools to use in clinical practice? Drugs Aging. 2005;22(3):231-255.

9. Schoen MD, DiDomenico RJ, Connor SE, Dischler JE, Bauman JL. Impact of the cost of prescription drugs on clinical outcomes in indigent patients with heart disease. Pharmacotherapy. 2001;21(12):1455-1463.

10. Kreyenbuhl J, Dixon LB, McCarthy JF, Soliman S, Ignacio RV, Valenstein M. Does adherence to medications for type 2 diabetes differ between individuals with vs without schizophrenia? Schizophr Bull. 2010;36(2):428-435.

11. Kennedy J, Tuleu I, Mackay K. Unfilled prescriptions of medicare beneficiaries: prevalence, reasons, and types of medicines prescribed. J Manag Care Pharm. 2008;14(6):553-560.

12. Polinski JM, Shrank WH, Huskamp HA, Glynn RJ, Liberman JN, Schneeweiss $\mathrm{S}$. Changes in drug utilization during a gap in insurance coverage: an examination of the medicare Part D coverage gap. PLoS Med. 2011;8(8):e1001075.

13. Federal Interagency Forum on Aging-Related Statistics. Older Americans 2012: Key indicators of well-being. Washington, DC: Federal Interagency Forum on Aging-Related Statistics; 2012. Available from: http://www.agingstats.gov/agingstatsdotnet/Main_Site/Data/2012_ Documents/docs/EntireChartbook.pdf. Accessed June 23, 2014.

14. Wroe AL. Intentional and unintentional nonadherence: a study of decision making. J Behav Med. 2002;25(4):355-372.

15. Hugtenburg JG, Timmers L, Elders PJ, Vervloet M, van Dijk L. Definitions, variants, and causes of nonadherence with medication: a challenge for tailored interventions. Patient Prefer Adherence. 2013;7:675-682.

Patient Preference and Adherence

\section{Publish your work in this journal}

Patient Preference and Adherence is an international, peer-reviewed, open access journal that focusing on the growing importance of patient preference and adherence throughout the therapeutic continuum. Patient satisfaction, acceptability, quality of life, compliance, persistence and their role in developing new therapeutic modalities and compounds to optimize Submit your manuscript here: http://www.dovepress.com/patient-preference-and-adherence-journal
16. Bubalo J, Clark RK Jr, Jiing SS, et al. Medication adherence: pharmacist perspective. J Am Pharm Assoc (2003). 2010;50(3):394-406.

17. Giberson S, Yoder S, Lee MP. Improving Patient and Health System Outcomes Through Advanced Pharmacy Practice: A Report to the U.S. Surgeon General 2011. Washington, DC: US Public Health Service; 2011. Available from: http://www.accp.com/docs/positions/misc/Improving Patient_and_Health_System_Outcomes.pdf. Accessed July 24, 2013.

18. Chisholm-Burns MA, Kim Lee J, Spivey CA, et al. US pharmacists' effect as team members on patient care: systematic review and metaanalyses. Med Care. 2010;48(10):923-933.

19. Chewning B, Schommer JC. Increasing clients' knowledge of community pharmacists' roles. Pharm Res. 1996;13(9):1299-1304.

20. Krueger JL, Hermansen-Kobulnicky CJ. Patient perspective of medication information desired and barriers to asking pharmacists questions. J Am Pharm Assoc (2003). 2011;51(4):510-519.

21. Ngoh LN. Health literacy: a barrier to pharmacist-patient communication and medication adherence. J Am Pharm Assoc (2003). 2009;49(5): e132-e146; quiz e147-e149.

22. Schommer JC. Patients' expectations and knowledge of patient counseling services that are available from pharmacists. Am J Pharm Educ. 1997;61(4):401-406.

23. Cooper JK, Love DW, Raffoul PR. Intentional prescription nonadherence (noncompliance) by the elderly. J Am Geriatr Soc. 1982;30(5): 329-333.

24. Patel RA, Lipton HL, Cutler TW, Smith AR, Tsunoda SM, Stebbins MR. Cost minimization of medicare part $\mathrm{D}$ prescription drug plan expenditures. Am J Manag Care. 2009;15(8):545-553.

25. Centers for Medicare and Medicaid Services (CMS). 2013 Medicare Part D Medication Therapy Management (MTM) Programs. Baltimore, MD: Centers for Medicare and Medicaid Services; 2013. Available from: http://www.cms.gov/Medicare/Prescription-Drug-Coverage/ PrescriptionDrugCovContra/Downloads/CY2013-MTM-Fact-Sheet. pdf. Accessed September 18, 2013.

26. Centers for Medicare and Medicaid Services (CMS). 2012 Medicare Part D Medication Therapy Management (MTM) Programs. Baltimore, MD: Centers for Medicare and Medicaid Services; 2012. Available from: http://www.cms.gov/Medicare/Prescription-Drug-Coverage/ PrescriptionDrugCovContra/Downloads/CY2012-MTM-Fact-Sheet. pdf. Accessed August 19, 2013.

27. New England Healthcare Institute (NEHI). Improving Patient Medication Adherence: Key Issues and Challenges in the Daily Practice of Medicine. Cambridge, MA: New England Healthcare Institute; 2013. Available from: http://www.nehi.net/writable/publication_files/file/improving_patient_ medication_adherence_key_issues_and_challenges_in_the_daily_ practice_of_medicine.pdf. Accessed September 10, 2013.

28. Raehl CL, Bond CA, Woods T, Patry RA, Sleeper RB. Individualized drug use assessment in the elderly. Pharmacotherapy. 2002;22(10): $1239-1248$.

29. O'Bryant CL, Crandell BC. Community pharmacists' knowledge of and attitudes toward oral chemotherapy. J Am Pharm Assoc (2003). 2008;48(5):632-639.

30. Morisky DE, Green LW, Levine DM. Concurrent and predictive validity of a self-reported measure of medication adherence. Med Care. 1986; 24(1):67-74.

31. Lavsa SM, Holzworth A, Ansani NT. Selection of a validated scale for measuring medication adherence. $J$ Am Pharm Assoc (2003). 2011; 51(1):90-94.

clinical outcomes for existing disease states are major areas of interest for the journal. This journal has been accepted for indexing on PubMed Central. The manuscript management system is completely online and includes a very quick and fair peer-review system, which is all easy to use. Visit http://www. dovepress.com/testimonials.php to read real quotes from published authors. 